\title{
Influence of the rheological behaviour of the lubricant on the appearance of pitting in elastohydrodynamic regime
}

\author{
J. ECHÁVARRI OTERO, E. DE LA GUERRA OCHOA, E. CHACÓN TANARRO, P. LAFONT MORGADO,
}

A. DÍAZ LANTADA, J. M. MUNOZ-GUIJOSA and J. L. MUÑOZ SANZ

ABSTRACT This paper analyses the influence of lubricant behaviour on the appearance of pitting. It attempts to study the effect of viscosity-pressure relation, compressibility, film thickness-roughness relation and friction coefficient on pitting failure of the contacting elements. To explain these effects, we first deal with the influence of the oil on the lubrication of the contact using elastohydrodynamic theory and secondly two multiaxial fatigue criteria are used, Crossland criterion and Dang Van criterion, to evaluate the influence of the rheology on the appearance of pitting. Finally, different applications are presented together with a discussion on the results obtained.

Keywords high-cycle fatigue; lubrication; multiaxial fatigue criterion; rolling contact fatigue (RCF); surface roughness.

NOMENCLATURE $a=$ half-width of the contact area (m)

$b=$ half-width of the contact area for triangular distribution (m)

$C_{1}, C_{2}, C_{3}=$ constants in the Höglund equation for density $(\mathrm{Pa})$

$D_{1}, D_{2}=$ constants in Dowson-Higginson equation for density $\left(\mathrm{Pa}^{-1}\right)$

$E^{\prime}=$ Reduced Young's modulus $(\mathrm{Pa}): \frac{1}{E^{\prime}}=\frac{1}{2}\left[\left(\frac{1-v_{1}^{2}}{E_{1}}\right)+\left(\frac{1-v_{2}^{2}}{E_{2}}\right)\right]$

$G=$ shear modulus of the lubricant $(\mathrm{Pa})$

$b=$ film thickness (m)

$b_{0}=$ minimum separation of the contacting surfaces in the case of rigid body approach (m)

$\mathcal{F}_{2}=$ second invariant of stress tensors $\left(\mathrm{Pa}^{2}\right)$

$\mathcal{F}_{2, a}=$ amplitude of the second invariant of stress tensors $\left(\mathrm{Pa}^{2}\right)$

$K=$ isotropic hardening parameter $(\mathrm{Pa})$

$m=$ safety coefficient of Melan's theorem

$n=$ Carreau's exponent

$p=$ pressure $(\mathrm{Pa})$

$p_{b}=$ hydrostatic pressure $(\mathrm{Pa})$

$p_{b, \text { max }}=$ maximum hydrostatic pressure in a cycle $(\mathrm{Pa})$

$p_{k}=$ peak pressure for triangular distribution $(\mathrm{Pa})$

$p_{0}=$ Hertz pressure $(\mathrm{Pa})$

$R_{\mathrm{x}}=$ contact radius in the direction $x(\mathrm{~m}): \frac{1}{R_{x}}=\frac{1}{R_{1 x}}+\frac{1}{R_{2 x}}$

$R(x, t)=$ contact roughness $(\mathrm{m})$

$r, r_{1}, r_{2}=$ geometric coordinates $(\mathrm{m})$

$\mathrm{SRR}=$ slide-to-roll ratio (\%), defined as $S R R(\%)=\frac{\Delta u}{u_{m}} \cdot 100$

$\mathrm{s}=$ deviatoric component of the mesoscopic stress tensor $(\mathrm{Pa})$ 


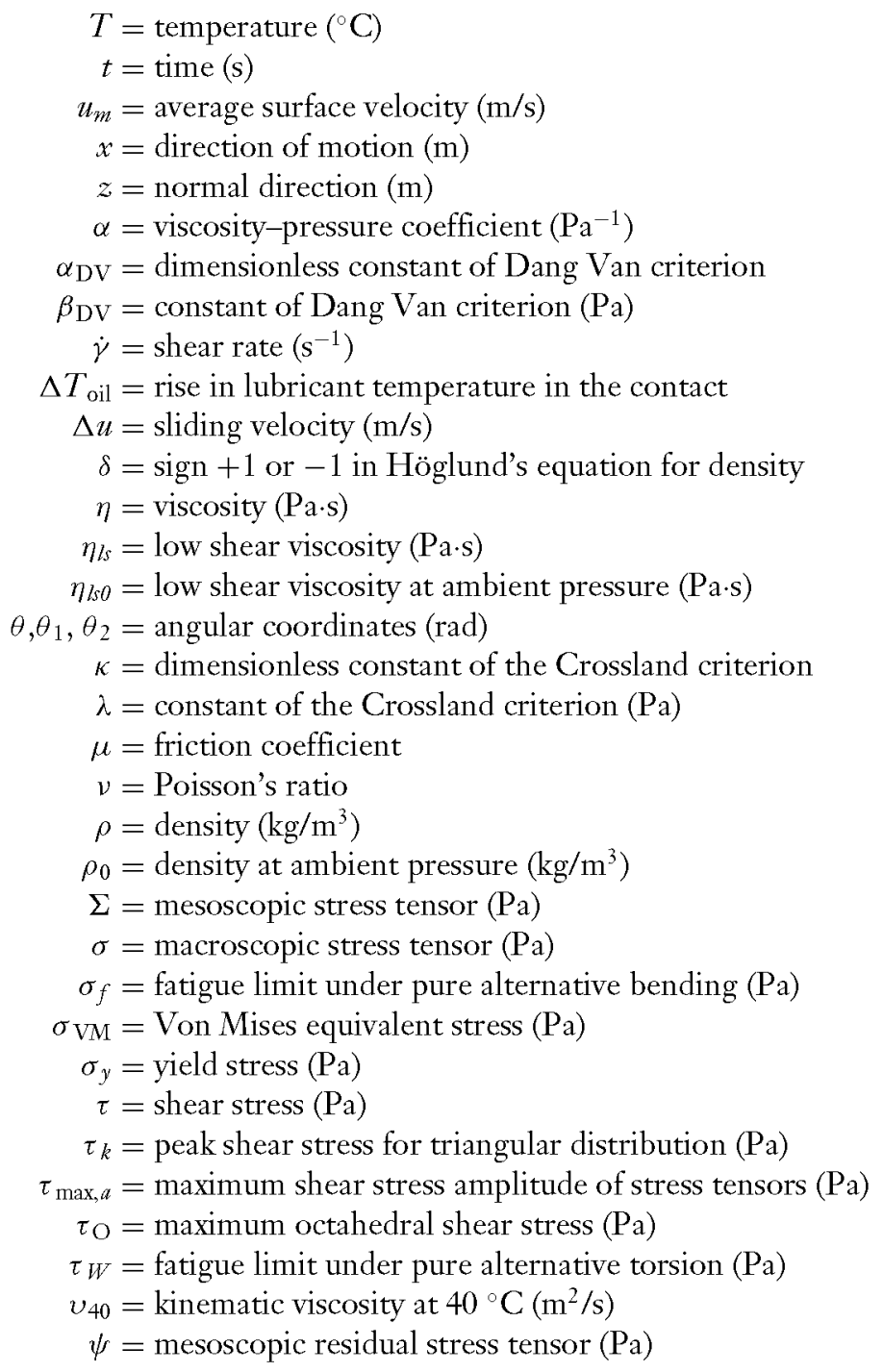

\section{INTRODUCTION}

Surface fatigue, like all fatigue phenomena, is due to the application of cyclical loads. Its appearance depends on the pressures and shear stresses reached in the contacts between mechanical elements subjected to rolling and sliding. ${ }^{1}$ The main consequence of surface fatigue is the appearance of different size pits on the surface depending on the scope of the damage (spalling, pitting or micropitting). These pits cause material loss and induce vibrations and overloads, which result in the element finally failing. This type of failure is typical of bearings, gears, ${ }^{2,3}$ the wheel-rail contact of trains ${ }^{4}$ and even artificial prostheses. ${ }^{5}$

Introducing lubricant into bearing or gear contacts may improve resistance to fatigue by obtaining fully flooded film and a decrease in friction. In order to test the effectiveness of lubricants in improving fatigue there is a wide range of normalized tests. 6,7

The study of the influence of lubrication will be conducted by solving the equations involved in elastohydrodynamic lubrication (EHL) ${ }^{8}$ : the Reynolds equation, the rheological behaviour and the elastic deformation equation in order to find the pressures and shear stresses in the contact. Once these have been calculated, the stresses inside the material are calculated so that the fatigue criterion can be finally applied.

For the study of cases of complex fatigue, such as the case we are dealing with, in recent years numerous multiaxial fatigue criteria have emerged. 9 In this paper, Dang Van and Crossland criteria are used. These allow a quantitative evaluation to be made of the influence of the lubricant 
rheology and the different parameters with influence on surface fatigue.

\section{LUBRICATION AND RHEOLOGICAL MODELS}

It is commonly accepted that under EHL line contacts the distribution of film thickness ${ }^{10-12}$ and pressure ${ }^{13}$ behave approximately in accordance with the Reynolds equation expressed as Eq. (1).

$\frac{\partial}{\partial x}\left(\frac{\rho h^{3}}{12 \eta} \frac{\partial p}{\partial x}\right)=u_{m} \frac{\partial(\rho b)}{\partial x}+\frac{\partial(\rho b)}{\partial t}$.

For this study the rise in contact temperature is considered as negligible and thus isothermal regime is assumed.

By applying the linear elastic theory to two semi-infinite, homogeneous and isotropic contacting bodies, the following expression is obtained for the lubricated film thickness.

$$
\begin{aligned}
b(x, t)= & b_{0}+\frac{x^{2}}{2 R_{x}}+R(x, t) \\
& +\frac{2}{\pi E^{\prime}} \int_{-\infty}^{+\infty} \ln \left(x-x^{\prime}\right)^{2} p\left(x^{\prime}\right) \mathrm{d} x^{\prime} .
\end{aligned}
$$

To numerically solve these equations, the Full MultiGrid techniques described by Venner and Lubrecht ${ }^{14}$ have been applied to obtain the pressure distribution and film thickness. The shear stress $(\tau)$ can be approached using the expression shown in Eq. (3). ${ }^{15}$

$$
\tau(x)=\eta(x) \dot{\gamma}(x) \approx \eta(x) \frac{\Delta u}{b(x)} .
$$

\section{Viscosity models}

For EHL the lubricant behaviour moves away from the Newtonian model. The Carreau model, ${ }^{16}$ shown in Eq. (4), has been used to represent the behaviour of the lubricant, where the low-shear viscosity is represented according to the Barus law. ${ }^{17}$

$$
\begin{aligned}
\eta(p, T, \dot{\gamma}) & =\eta_{l s}(p, T)\left[1+\left(\frac{\eta_{l s}(p, T)}{G} \dot{\gamma}\right)^{2}\right]^{\frac{n-1}{2}} \\
& =\eta_{l s 0}(T) e^{\alpha(T) p}\left[1+\left(\frac{\eta_{l s 0}(T) e^{\alpha(T) p}}{G} \dot{\gamma}\right)^{2}\right]^{\frac{n-1}{2}} .
\end{aligned}
$$

\section{Density models (Compressibility)}

Diverse experimental models have been used for the variation in density with pressure of different lubricants, such as the Höglund ${ }^{18}$ and the Dowson-Higginson ${ }^{19}$ models shown in Eqs (5) and (6), respectively, where coefficients
$C_{1}, C_{2}, C_{3}, D_{1}, D_{2}$ and $\delta$, are adjusted to experimental data.

$$
\begin{aligned}
& \frac{\rho(p)}{\rho_{0}}=\left[1+\frac{C_{1}}{2 C_{2}}\left(1+\delta \sqrt{1+\frac{4 C_{2}\left(p-C_{3}\right)}{C_{1}^{2}}}\right)\right]^{-1} \\
& \frac{\rho(p)}{\rho_{0}}=1+\frac{D_{1} p}{1+D_{2} p} .
\end{aligned}
$$

\section{PREDICTING THE APPEARANCE OF SURFACE FATIGUE}

Once the pressure and the shear stress in the contact are known, the macroscopic stresses inside the material can then be calculated, the material being taken as a semiinfinite elastic solid bounded by a plane surface. Due to this idealization of the solid, it can be considered to have a state of plane strain. ${ }^{20}$

Figure 1 represents an outline of the solid, axes and triangular distribution of pressure and shear stress.

To solve the stress field induced by whatever distribution of $p(x)$ and $\tau(x)$, the principle of superposition is used. That is, the original distributions are divided into a series of equivalent triangular distributions $\left(p_{k}(x)\right.$ and $\left.\tau_{k}(x)\right),{ }^{21}$ shown in Fig. 1, because these have an analytical solution for the stress field, Eq. (7).

$$
\begin{aligned}
& p_{k}(x)=p_{k}\left(1-\frac{|x|}{b}\right),|x| \leq b \\
& \tau_{k}(x)=\tau_{k}\left(1-\frac{|x|}{b}\right),|x| \leq b .
\end{aligned}
$$

The solution to the stress field resulting from the triangular distribution (pressure and shear stress) is given by the following expressions ${ }^{21}$ :

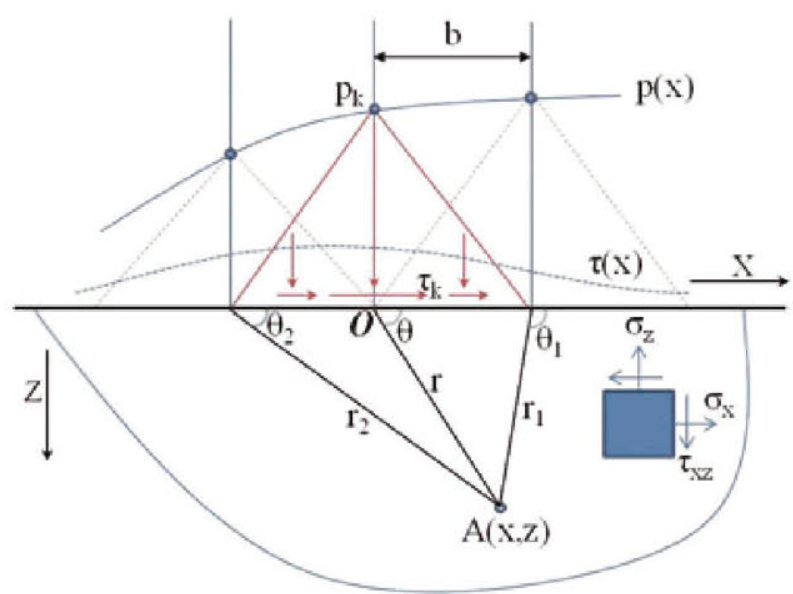

Fig. 1 Diagram of line contact and triangular distribution of pressure and shear stress. 


$$
\begin{aligned}
\sigma_{x}^{k}= & \frac{p_{k}}{\pi b}\left\{(x-b) \theta_{1}+(x+b) \theta_{2}-2 \theta x+2 z \ln \left(\frac{r_{1} r_{2}}{r^{2}}\right)\right\} \\
& +\frac{\tau_{k}}{\pi b}\left\{2 x \ln \left(\frac{r_{1} r_{2}}{r^{2}}\right)+2 b \ln \left(\frac{r_{2}}{r_{1}}\right)-3 z\left(\theta_{1}+\theta_{2}-2 \theta\right)\right\} \\
\sigma_{z}^{k}= & \frac{p_{k}}{\pi b}\left\{(x-b) \theta_{1}+(x+b) \theta_{2}-2 \theta x\right\} \\
& -\frac{\tau_{k} z}{\pi b}\left\{\theta_{1}+\theta_{2}-2 \theta\right\} \\
\sigma_{y}^{k}= & v\left(\sigma_{x}^{k}+\sigma_{z}^{k}\right) \\
\tau_{x z}^{k}= & -\frac{p_{k} z}{\pi b}\left\{\theta_{1}+\theta_{2}-2 \theta\right\}+\frac{\tau_{k}}{\pi b}\left\{(x-b) \theta_{1}\right. \\
& \left.+(x+b) \theta_{2}-2 \theta x+2 z \ln \left(\frac{r_{1} r_{2}}{r^{2}}\right)\right\},
\end{aligned}
$$

where the geometric variables reflected in Fig. 1 are as follows:

$$
\begin{aligned}
& r_{1}^{2}=(x-b)^{2}+z^{2} \\
& r_{2}^{2}=(x+b)^{2}+z^{2} \\
& r^{2}=x^{2}+z^{2} \\
& \tan \left(\theta_{1}\right)=\frac{z}{x-b} \\
& \tan \left(\theta_{2}\right)=\frac{z}{x+b} \\
& \tan (\theta)=\frac{z}{x} .
\end{aligned}
$$

By applying the principle of superposition to each point $A(x, z)$.

$$
\begin{aligned}
\sigma_{x} & =\sum_{k=1}^{N} \sigma_{x}^{k} ; \quad \sigma_{y}=\sum_{k=1}^{N} \sigma_{y}^{k} ; \quad \sigma_{z}=\sum_{k=1}^{N} \sigma_{z}^{k} ; \\
\tau_{x z} & =\sum_{k=1}^{N} \tau_{x z}^{k} .
\end{aligned}
$$

Now that the macroscopic stresses are known, the mesoscopic stresses or grain level stresses can be calculated, as this is where the cracks first appear. The mesoscopic stresses $(\Sigma)$ are related to the previously calculated macroscopic stresses $(\sigma)$, using the mesoscopic residual stress tensor $(\psi)^{2,22}$

$\sum=\sigma+\psi$.

In order to find the mesoscopic residual stresses, Melan's theorem is used, Eq. (12), which proposes an elastic shakedown-based method, ${ }^{22}$ where the function $f$ represents the yield criteria or yield surface.

$f(m \sigma(x, t)+\psi(x))-K^{2} \leq 0$.

Figure 2 shows a series of stress-strain cycles where the material's elastic limit is exceeded. When this happens, the material undergoes a hardening that is both isotropic and kinematic. ${ }^{23}$ That is, an increase and a displacement in the yield surface of the material are produced, which, after a number of cycles, leads to a stabilized pure elastic cycle.

Following the Von Mises criterion, the yield surface $(f)$ is defined by Eq. (13), which represents a six-dimension hypersphere.

$-\mathcal{f}_{2}-K^{2}=0$

$\left(\frac{s_{x}^{2}+s_{y}^{2}+s_{z}^{2}}{2}+s_{x y}^{2}+s_{x z}^{2}+s_{y z}^{2}\right)-K^{2}=0$.

Therefore, the problem can be solved by calculating the radius $(K)$ and the centre $(-\psi)$ of a hypersphere that contains all the points of the time history of the macroscopic elastic stresses. Mathematically, this is expressed as an optimization problem for the calculation of the hypersphere of least radius containing the time history. ${ }^{24}$
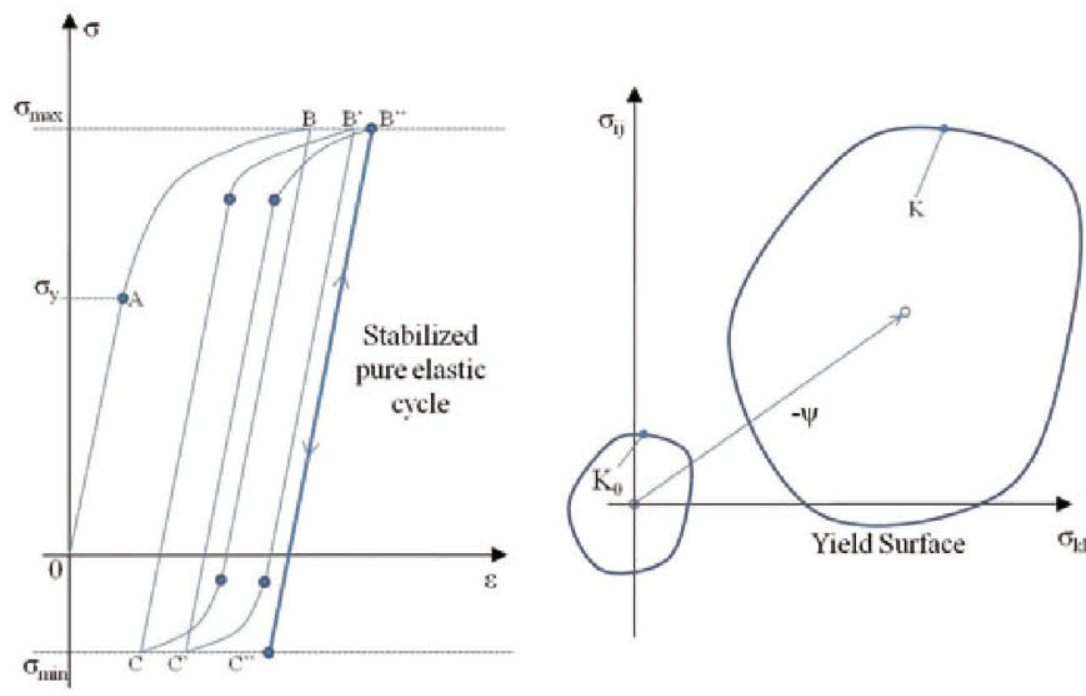

Fig. 2 Elastic shakedown and isotropic and kinematic hardening. 
In order to check the severity of the contact during the load cycle, from a fatigue point of view, the Crossland and Dang Van multiaxial fatigue criteria are used.

\section{The Dang Van criterion}

This criterion has been widely used in the literature to predict life to surface fatigue ${ }^{2,4,25}$ and sets in Eq. (14) to find out when the beginning of cracks is not produced.

$\tau_{\max , a}(t)+\alpha_{D V} p_{b}(t) \leq \beta_{D V}$,

where the expression for $\tau_{\max , a}$ and $p_{b}$ are contained in Eq. (15).

$$
\begin{aligned}
\tau_{\max , a}(t) & =\frac{s_{1 a}(t)-s_{3 a}(t)}{2} \\
p_{b}(t) & =\frac{1}{3}\left(\Sigma_{x}(t)+\Sigma_{y}(t)+\Sigma_{z}(t)\right) \\
& =\frac{1}{3}\left(\Sigma_{1}(t)+\Sigma_{2}(t)+\Sigma_{3}(t)\right)
\end{aligned}
$$

where $s_{1,3 a}$ are the major and minor principal stresses of the alternative part of the deviatoric mesoscopic stress tensor.

Parameters $\alpha_{\mathrm{DV}}$ and $\beta_{\mathrm{DV}}$ are material constants that are calculated from pure torsion $\left(\tau_{W}\right)$ and pure bending $\left(\sigma_{f}\right)$ fatigue tests for a determined number of cycles. ${ }^{25}$

$\beta_{\mathrm{DV}}=\tau_{W}$

$\alpha_{\mathrm{DV}}=3\left(\frac{\tau_{W}}{\sigma_{f}}-\frac{1}{2}\right)$.

\section{The Crossland criterion}

The Crossland criterion is based on the second invariant of stresses and sets the following relation to avoid the appearance of fatigue.

$\sqrt{7_{2, a}(t)}+\kappa p_{b, \max } \leq \lambda$.

As in the previous example, $\lambda$ and $\kappa$ are material constants and are calculated likewise. ${ }^{26}$

$\kappa=\frac{3 \tau_{w}}{\sigma_{f}}-\sqrt{3}$

$\lambda=\tau_{W}$.

By re-writing both criteria and particularizing for the most unfavourable load cycle conditions, the following is given:

Dang Van $\rightarrow \beta_{e q}=\max _{t}\left(\tau_{\max , a}(t)+\alpha_{D V} p_{b}(t)\right) \leq \beta_{D V}$

Crossland $\rightarrow \lambda_{e q}=\max _{t}\left(\sqrt{\mathcal{F}_{2, a}(t)}+\kappa p_{b, \max }\right) \leq \lambda$.
As can be seen in Eqs (16) and (18), $\beta_{\mathrm{DV}}$ and $\lambda$ are equal to fatigue limit under pure alternative torsion $\left(\tau_{W}\right)$. Therefore, if the criteria were completely equivalent they should result in the same values, that is $\lambda_{e q}=\beta_{e q}$. This means that the contact severity can be measured by using just one single parameter: $\lambda_{e q}$ or $\beta_{e q}$. The higher the severity, the more the contact will be subjected to fatigue, and the closer it will be to failure conditions.

In order to apply multiaxial fatigue criteria, macroscopic and mesoscopic stress field can be calculated using Eqs (8), (11) and (13). For this purpose a previous step is to find the pressure and shear stress distributions by solving the EHL equations shown in Eqs (1) to (3). In this way, the effect of the rheology of the lubricant on the appearance of pitting can be explained and predicted.

\section{RESULTS AND DISCUSSION}

In order to study the effect of viscosity-pressure coefficient $(\alpha)$, compressibility, friction coefficient $(\mu)$ and film thickness $(b)$ three different oils were chosen: LVI260, 5P4E and PAO6. LVI260 is a mixture of different bases with high naphthenic content, ${ }^{27} 5 \mathrm{P} 4 \mathrm{E}$ is a mixture of isomers of a five-ring polyphenyl ether used for turbines ${ }^{28}$ and PAO6 is a low-viscosity polyalphaolefin used for gears. The most suitable density model was taken for each lubricant, whose properties are shown in Tables 1 and 2. All the data were measured at constant temperature $(T=$ $40^{\circ} \mathrm{C}$ ).

Table 2 includes the base type and the kinematic viscosity, which means piezoviscosity can be predicted for other temperatures. ${ }^{32}$

The operating conditions are such that they guarantee EHL lubrication regime for the different oils, bearing in mind their different properties. The input conditions selected and the corresponding calculations of friction coefficient, film thickness and shear rate are shown in Table 3.

To verify the isothermal hypothesis a rough estimation is made of the rise in temperature of the lubricant in the contact, using an analytical method ${ }^{33}$ based on expressions for line contacts: Hamrock's ${ }^{28}$ formula for central film thickness $\left(b_{c}\right)$ and thermal considerations. ${ }^{34}$ The rise in lubricant temperature in the contact $\left(\Delta T_{\text {oil }}\right)$ is negligible, as can be seen in Table 3 .

The highest values of the viscosity-pressure coefficient produce an increase in the pressure peaks of the EHL distribution and an increase in film thickness. ${ }^{15}$ On the other hand, the compressibility reduces the size of the peak and causes a decrease in the central film thickness, while the minimum thickness hardly varies. ${ }^{18}$ Figure 3 shows the effect of the calculated compressibility on the pressure and shear stress distributions. 
Table 1 Density model constants

\begin{tabular}{|c|c|c|c|c|c|}
\hline Lubricant & $C_{1}(\mathrm{~Pa})$ & $C_{2}(\mathrm{~Pa})$ & $C_{3}(\mathrm{~Pa})$ & $\delta$ & $\rho_{0}\left(\mathrm{~kg} / \mathrm{m}^{3}\right)$ \\
\hline PAO $6^{18}$ & 1 & 24.50 & 0 & -1 & 830 \\
\hline Lubricant & $D_{1}\left(\mathrm{GPa}^{-1}\right)$ & $D_{2}\left(\mathrm{GPa}^{-1}\right)$ & $\rho_{0}\left(\mathrm{~kg} / \mathrm{m}^{3}\right)$ & & \\
\hline LVI260 ${ }^{19,28,29}$ & 0.64 & 2.89 & 929 & & \\
\hline $5 \mathrm{P} 4 \mathrm{E}^{18,19,28,29}$ & 0.60 & 1.70 & 1184 & & \\
\hline
\end{tabular}

Table 2 Viscosity parameter values

\begin{tabular}{|c|c|c|c|c|c|c|}
\hline Lubricant & Base type & $\alpha\left(\mathrm{GPa}^{-1}\right)$ & $\eta_{\mathrm{ls} 0}(\mathrm{mPa} \cdot \mathrm{s})$ & $v_{40}\left(\mathrm{~mm}^{2} / \mathrm{s}\right)$ & $n$ & $\mathrm{G}(\mathrm{MPa})$ \\
\hline PAO $6^{30}$ & Polyalphaolefin (synthetic) & 11.50 & 25 & 30.24 & 0.53 & 1.59 \\
\hline LVI260 28,31 & Naphthenic mineral oil & 30.17 & 428 & 460.71 & 0.34 & 5.60 \\
\hline $5 \mathrm{P} 4 \mathrm{E}^{28}$ & Ether (synthetic) & 35 & 340 & 287.16 & 0.68 & 4 \\
\hline
\end{tabular}

Table 3 Operating conditions

\begin{tabular}{lllllllll}
\hline Lubricant & $p_{0}(\mathrm{MPa})$ & $u_{m}(\mathrm{~m} / \mathrm{s})$ & SRR $(\%)$ & Materials & $\mu$ & $b_{c}(\mathrm{~nm})$ & $\dot{\gamma}\left(\mathrm{s}^{-1}\right)$ & $\Delta T_{\text {oil }}\left({ }^{\circ} \mathrm{C}\right)$ \\
\hline PAO6 & 828 & 2 & 25 & Steel & 0.02 & 184 & $2.7 \mathrm{E} 6$ & 3.4 \\
LVI260 & 828 & 0.1 & 10 & Steel & 0.04 & 267 & $3.7 \mathrm{E} 4$ & 0.4 \\
5P4E & 828 & 0.1 & 10 & Steel & 0.08 & 245 & $4.1 \mathrm{E} 4$ & 0.6 \\
\hline
\end{tabular}
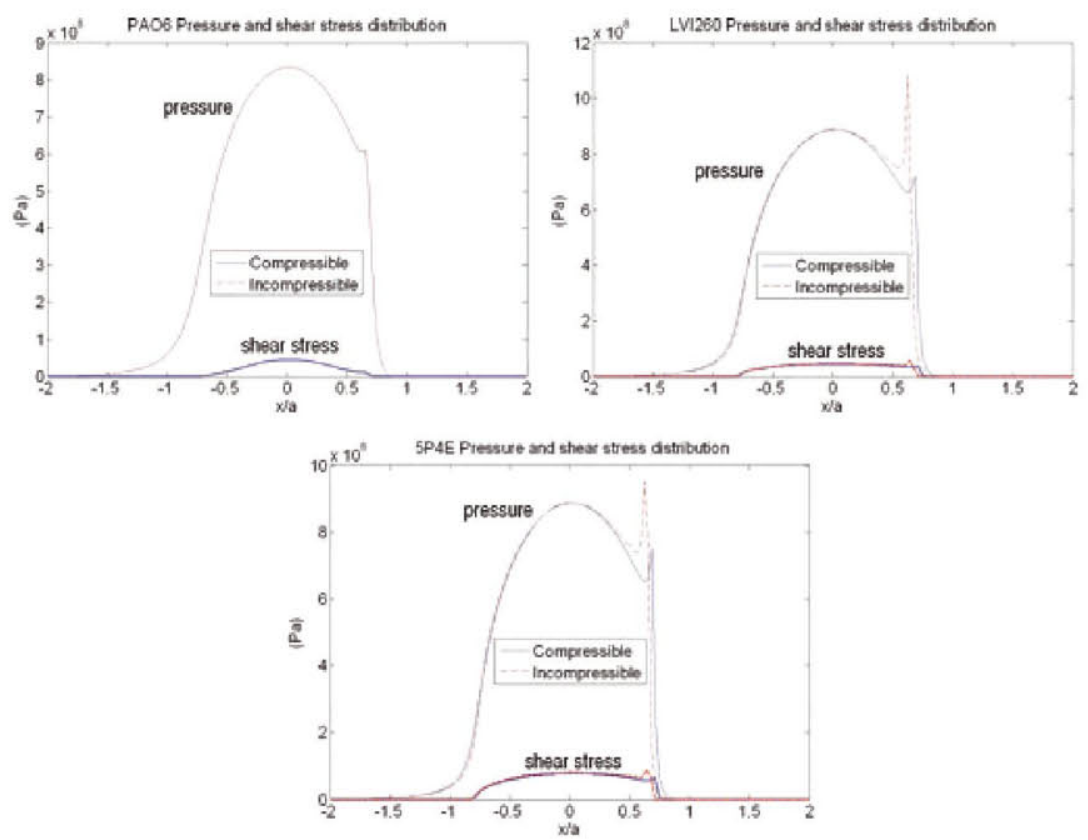

Fig. 3 Pressure and shear stress distribution for 5 P4E, LVI260 and PAO6 with the compressible and incompressible models.

Changes in the pressure field and shear stress distribution also affect the calculated stress field. Figure 4 reflects the elastic stress fields obtained for the three lubricants with the compressible and incompressible models. The values and location of Maximum Von Mises, $\left(\sigma_{\mathrm{VM}}\right)_{\max }$, and Maximum octahedral shear stress, ${ }^{35}\left(\tau_{0}\right)_{\max }$, made dimensionless with the Hertz pressure $p_{0}$, are depicted in Fig. 4.

Figure 4 shows the effect of the viscosity. The main parameter of influence on the viscosity is the viscosity-pressure coefficient $(\alpha)$, whose increase leads to a higher EHL distribution pressure peak, which in turn 

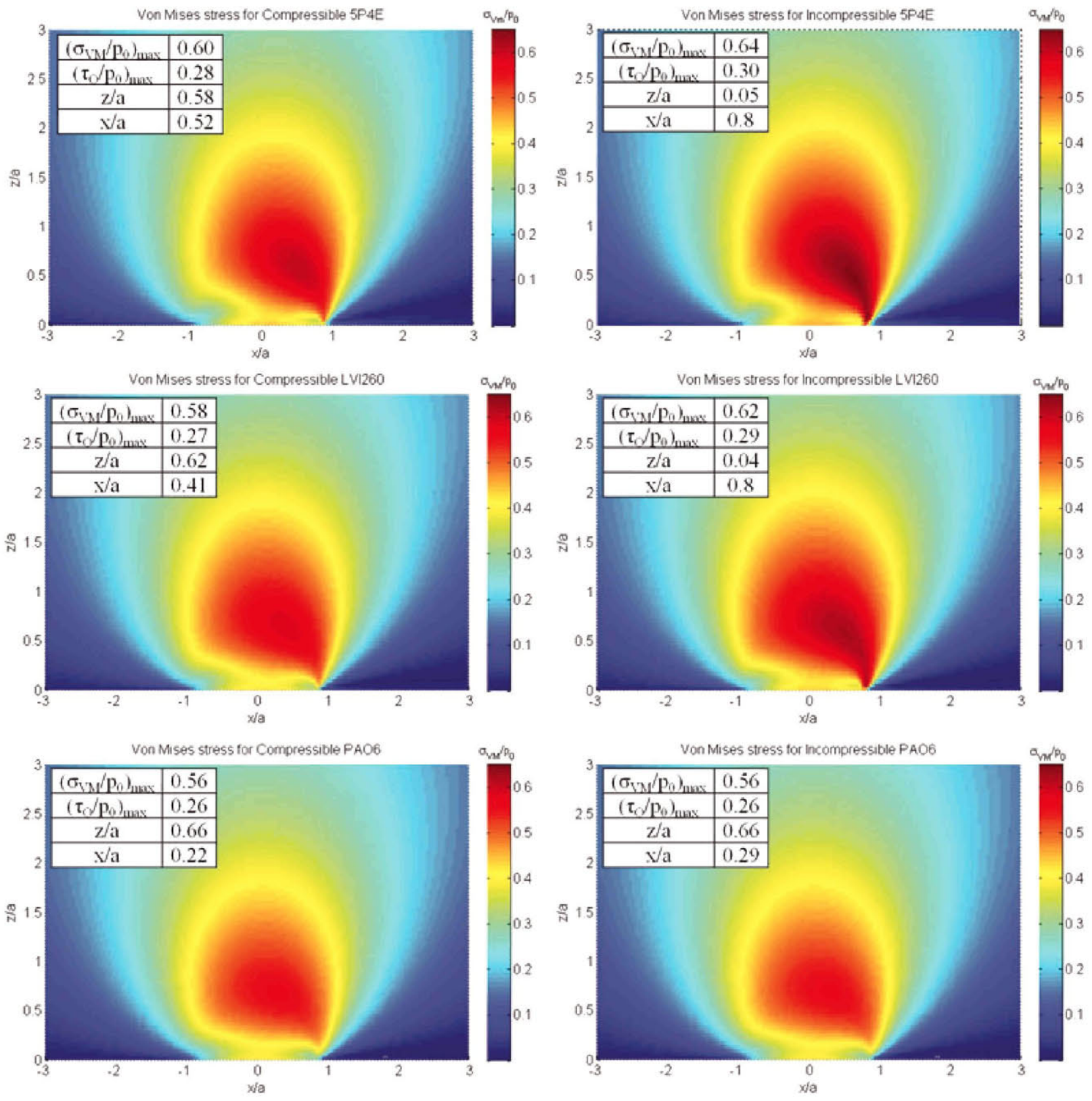

Fig. 4 Elastic stress fields calculated for 5P4E, LVI260 and PAO6 with the compressible and incompressible model.

leads to higher stress levels. Thus it can be justified that the lowest value of $\left(\sigma_{\mathrm{VM}} / p_{0}\right)_{\max }$ corresponds to PAO- 6 , which exhibits the smallest $\alpha$ of the three lubricants considered. Likewise, the highest stress values correspond to lubricant 5P4E with the highest $\alpha$. Finally, LVI260 presents an in-between case.

It should be pointed out that the difference between the viscosity-pressure coefficients $(\alpha)$ of LVI260 and 5P4E is not very large, but the latter exhibits significantly higher stresses due to the additional contribution of friction to the increase in stress. As already shown, the value of the friction coefficient for 5P4E doubles that of LVI260. In addition a high viscosity-pressure coefficient usually induces an increase in the friction coefficient, ${ }^{18,36,37}$ which causes the contact stress levels to increase further.

The compressibility effect can be seen in Fig. 4 by comparing the compressible and incompressible cases. As the compressibility rises a decrease in the EHL peak pressure can be appreciated (Fig. 3), leading to lower stress levels apart from causing the critical stress point to move away from the surface. In the case of the PAO6 there are no 

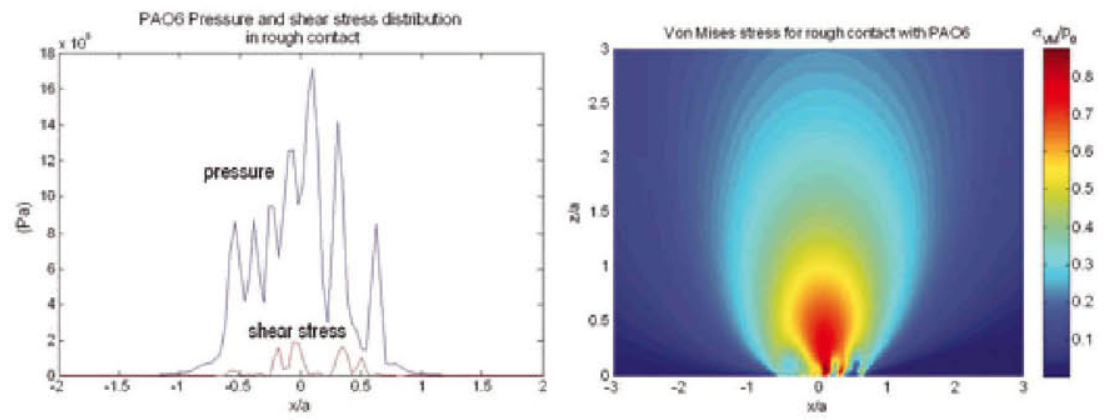

Fig. 5 Pressure and shear stress distribution and elastic stress field for the rough EHL case with PAO6. differences, due to the fact that under the given conditions, the pressure peak is very small due to its low $\alpha$ value, while it can be observed that its pressure distribution in the contact is very similar to the Hertz pressure (Fig. 3).

If the rough contacts are taken into account, then a rough EHL calculation can be performed by inserting a random $R(x, t)$ function into Eq. (2). The roughness value selected is $R_{a}=30 \mathrm{~nm}$ so that there would be a complete film without there being any metal contact. The result is that the pressure distribution exhibits very high pressure peaks induced by roughness. ${ }^{2,38}$ The effect of roughness on the pressure distribution is reflected in the stress field obtained, shown in Fig. 5, which reflects the incompressible case of the PAO6. Moreover, it can be seen that the influence of roughness mainly affects the zones close to the surface. ${ }^{11,39}$

If the rough and smooth results are compared, the differences can be clearly seen, not only in the change of shape of the distribution but also the stress levels have clearly increased, passing from $\left(\sigma_{\mathrm{VM}} / p_{0}\right)_{\max }=0.56$ to $\left(\sigma_{\mathrm{VM}} / p_{0}\right)_{\max }=0.86($ at $x / a=0.11$ and $z / a=0.05)$ for the rough case.

When the influence on the stress field has been seen, we can then go on to apply the fatigue criteria. The results obtained are shown in Fig. 6 for the different case studies. The values $\lambda_{e q}$ and $\beta_{e q}$ in Eq. (19) have been represented according to the depth of the material, $z / a$, with the purpose of locating the point of critical fatigue in the inside of the material.

In order to use these criteria, the C45E steel was considered, the composition and properties of which are provided in Table 4 . This is the usual material used to manufacture gears, and moreover the pure bending and pure torsion fatigue tests data ${ }^{40}$ are available for comparing the results with different oils.

The results of the fatigue criteria (Fig. 6) represent the contact severity in different cases, taking account of the stress field obtained with each lubricant (Figs 4 and 5), and also help to numerically evaluate this influence, by means of the corresponding critical fatigue point indicated in Fig. 6.
What is first noticeable is the difference between the results obtained by one criterion or another. It is known that the Dang Van criterion overestimates material properties giving lower severity values than the Crossland criterion $\left(\lambda_{e q}>\beta_{e q}\right),{ }^{25,26}$ mainly due to the excessive weight given to the hydrostatic pressure by the Dang Van criterion. This fact influences the other difference between the two criteria: the location of the critical point from a fatigue point of view, as Fig. 6 illustrates.

In the formulation of the Dang Van criterion, Eq. (14), there is the hydrostatic pressure component $\left(p_{b}\right)$ and the maximum shear stress component $\left(\tau_{\max , a}\right)$. This gives rise to two local maximums:

- A maximum close to the surface ( $z / a$ between 0 and 0.03$)$, induced by the high hydrostatic pressure $\left(p_{b}\right)$ due to the pressure peaks of the EHD contact observed in Fig. 3. The hydrostatic pressure is maximum in the zones close to the surface and drops rapidly as the depth increases. ${ }^{41}$

- A second maximum at a greater depth $(z / a \approx 0.8)$, near to the maximum shear stress zone $\left(\tau_{\max , a}\right)$ of the contact. The shear stress grows from the surface, where there is shear stress due to friction, up to a maximum value that is found at a maximum depth of approximately $z / a=0.786$. This depth is similar to that described in the case of frictionless Hertzian line contact ${ }^{41}$ due to the low values of the friction coefficient.

Depending on the hydrostatic pressure and shear stress values reached in each case, the absolute maximum will be found in one zone or another. If the pressure peaks are small, the local maximum induced by the shear stress will be dominant and become the critical fatigue failure point. This can be seen in Fig. 6, when considering a smooth contact or a compressible lubricant, as in these cases, the pressure peaks are diminished (Figs 3 and 5).

On the other hand, according to the Crossland criterion, the failure zone is found in other location. Due to the formulation of the criterion, Eq. (17), the hydrostatic term $\left(p_{b, \max }\right)$ is less important, which takes the failure zone away from the surface. As a result, the dominant term is usually the second invariant of the deviatoric component 
Fig. 6 The Dang Van and Crossland criteria for 5P4E, smooth $\mathrm{PAO} 6$ and rough PAO6.
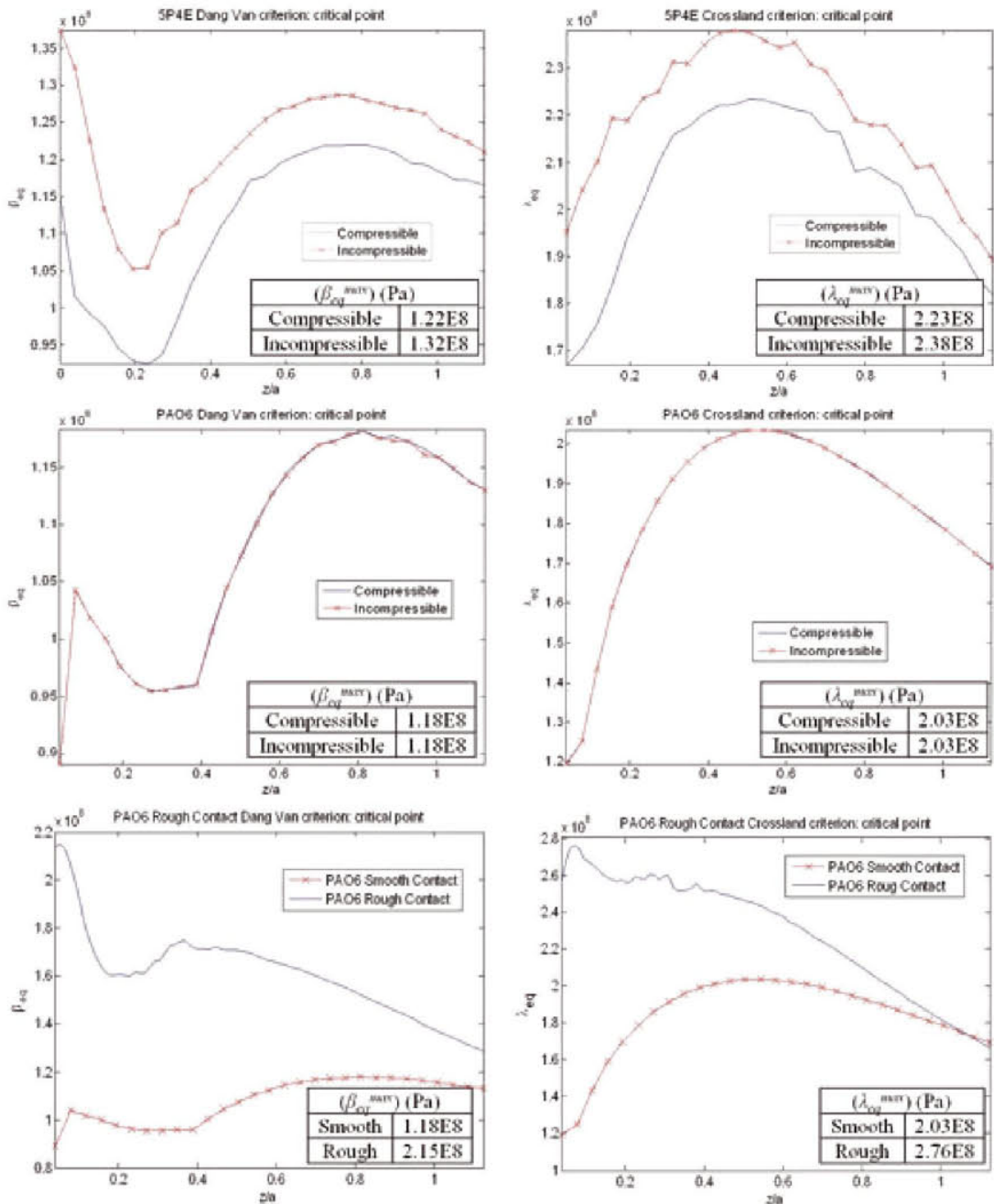

Table 4 Properties of $\mathrm{C} 45 \mathrm{E}$

$\mathrm{C} 45 \mathrm{E}$

\begin{tabular}{|c|c|c|c|c|c|c|c|c|c|c|}
\hline \multicolumn{6}{|c|}{ Composition } & \multicolumn{5}{|c|}{ Mechanical properties } \\
\hline C & $\mathrm{Si}$ & $M n$ & $P$ & $S$ & $N$ & $\sigma_{y}(\mathrm{MPa})$ & $\beta_{\mathrm{DV}}(\mathrm{MPa})$ & $\alpha_{\mathrm{DV}}$ & $\lambda(\mathrm{MPa})$ & $\kappa$ \\
\hline $0.45 \%$ & - & $0.65 \%$ & - & - & - & $650-800^{*}$ & 287 & 0.54 & 287 & 0.30 \\
\hline
\end{tabular}

${ }^{*}$ Mean strength in quenched and tempered condition.

of the mesoscopic stress tensor $\left(\sqrt{\mathcal{F}_{2, a}(t)}\right)$. For this reason, frequently a single maximum appears for the Crossland criterion corresponding to the function $\sqrt{\mathcal{F}_{2, a}(t)}$, that is to say, in positions ${ }^{26} z / a \approx 0.5$, as Fig. 6 shows.

If we finally compare the rheological models, we find the following influences, according to Crossland criterion:

- The effect of the viscosity-pressure and friction coefficient: these two factors are analysed together because they are very closely related, as a decrease in the value of $\alpha$, under the same operating conditions, means a decrease in the value of the friction coefficient. If the cases of Compressible 5P4E are compared with $\mathrm{PAO}$, we find a $67 \%$ decrease in the $\alpha$ coefficient, which, in turn, has an associated decrease of $75 \%$ in the friction coefficient, which, in all, means a $10 \%$ decrease in severity.

- Compressibility effect: comparing the compressible and incompressible models of $5 \mathrm{P} 4 \mathrm{E}$, we find that the compressible model supposes a $7 \%$ decrease in the severity of the contact for this lubricant. 
- Roughness: the cases studied were the PAO6 with smooth EHL contact and PAO6 with rough EHL contact. By referring to Fig. 6, it can be seen that an increase in roughness considerably increases contact severity. Therefore, the less roughness, the smoother the pressure distribution in the contact, and therefore, the life to fatigue of the contact will be better. In this case, for the Crossland criterion, we have a $26 \%$ decrease in the critical value of $\lambda_{e q}$ for the smooth case compared to the rough case.

If it is wished to optimize the factor with most weight, which is the roughness factor, the film thickness can be increased. To do this, under equal operating conditions, the value of the viscosity-pressure value needs to be increased, which has been seen to have an opposite effect on the pressure peak and the life.

\section{CONCLUSIONS}

This paper has presented a methodology for predicting pitting in contacts with EHL lubrication, including an indepth study of the influence of rheological models on the calculation of the life by taking different multiaxial fatigue criteria.

Taking into account the rheological characterization of the lubricant for the operating conditions of the contact, the EHL behaviour can be found (pressures, film thickness or friction coefficient), the stress calculations and the evaluation of the contact severity.

Three lubricants with different rheological properties have been analysed, verifying that the life to fatigue improves in the following cases: high compressibility, low viscosity-pressure coefficient and high specific film thickness and low roughness. As a result, optimizing the life to surface fatigue is complex because the parameters with influence are interdependent and on occasions have opposite effects.

\section{REFERENCES}

1 Bhushan, B. (2002) Introduction to Tribology. John Willey \& Sons, USA.

2 Brandao, J. A., Seabra, J. and Castro, J. (2010) Surface initiated tooth flank damage. Part I: Numerical model. Wear 268, 1-12.

3 Aslantas, K. and Tasgetiren, S. (2004) A study of spur gear pitting formation and life prediction. Wear 257, 1167-1175.

4 Ekberg, A. (1997) Rolling contact fatigue of railway wheels- a parametric study. Wear 211, 280-288.

5 Kennedy, F. E., Currier, J. H., Plumet, S., Duda, J. L., Gestwick, D. P., Collier, J. P., Currier, B. H. and Dubourg, M. C. (2000) Contact fatigue failure of ultra-high molecular weight polyethylene bearing components of knee prostheses. 7. Tribol. 122, 332-339.

6 International Organization for Standardization (ISO) (1996) ISO/DIS 12925-1 CKC: Lubricants, industrial oils and related products (class L) - Family C (Gears) - Part 1: Specifications for lubricants for enclosed gear systems. Switzerland.

7 Forschungsvereinigung Antriebstechnik E.V. (1993) FVA Researcb Project Nr. 54/I-IV: Test Procedure for the Investigation of the Micro-Pitting Capacity of Gear Lubricants. Germany.

8 Jang, J. Y., Khonsari, M. M. and Bair, S. (2007) On the elastohydrodynamic analysis of shear-thinning fluids. Proc. $R$. Soc. London, Ser. A 463, 3271-3290.

9 Papadopoulos, I. V., Davoli, P., Gorla, C., Filippini, M. and Bernasconi, A. (1997) A comparative study of multiaxial highcycle fatigue criteria for metals. Int. F. Fatigue 19, 219-235.

10 Greenwood, J. A. (1999) Two-dimensional flow of a non-Newtonian lubricant. Proc. Instn. Mech. Engrs., Part 7 214, 29-41.

11 Zhu, D., Ren, N. and Wang, Q. J. (2009) Pitting life prediction based on a $3 \mathrm{D}$ line contact mixed EHL analysis and subsurface Von Mises stress calculation. 7. Tribol. 131, 041501.

$12 \mathrm{Hu}, \mathrm{Y}$. and Zhu, D. (2000) A full numerical solution to the mixed lubrication in point Contacts. 7. Tribol. 122, 1-9.

13 Dowson, D. (1995) Elastohydrodynamic and micro-elastohydrodynamic lubrication. Wear 190, 125-138.

14 Venner, C. H. and Lubrecht, A. A. (2000) Multilevel Methods in Lubrication. Elsevier. Tribology Series, vol. 37.

15 Gohar, R. and Rahnejat, H. (2008) Fundamentals of Tribology. Imperial College Press, UK.

16 Carreau, P. J. (1972) Rheological equations from molecular network theories. Trans. Soc. Rheol., 16, 99-127.

17 Barus, C. (1893) Isothermals, isopiestics and isometrics relative to viscosity. Am. 7. Sci. 45, 87-96.

18 Höglund, E. (1999) Influence of lubricant properties on elastohydrodynamic lubrication. Wear, 232, 176-184.

19 Larsson, R., Larsson, P. O., Eriksson, E., Sjöberg, M. and Höglund, E. (2000) Lubricant properties for input to hydrodynamics and elastohydrodynamic lubrication analyses. Proc. Instn. Mech. Engrs., Part 7 214, 17-27.

20 Pehan, S., Hellen, T. K., Flasker, J. and Glodez, S. (1997) Numerical methods for determining stress intensity factors vs. crack depth in gear tooth roots. Int. 7. Fatigue 19, 617-685.

21 Johnson, K. L. (1985) Contact Mechanics. Cambridge University Press, UK.

22 Constantinescu, A., Dang Van, K. and Maitournam, M. H. (2003) A unified approach for high and low cycle fatigue based on shakedown concepts. Fatigue Fract. Engng Mater. Struct. 26, 561-568.

23 Zubizarreta, V. and Ros, A. (2003) Introducción a la mecánica de los sólidos. Sección de Publicaciones de la E.T.S.I. Industriales de la Univ. Politécnica de Madrid, Madrid, Spain.

24 Kumar, P., Mitchell, J. S. B. and Yildimirin, A. (2003) Computing core-sets and approximate smallest enclosing byperspheres in high dimensions. http://www.compgeom.com/ meb/.

25 Desimone, H., Bernasconi, A. and Beretta, S. (2006) On the application of Dang Van criterion to rolling contact fatigue. Wear 260, 567-572.

26 Ciavarella, M. and Monno, F. (2010) A comparison of multiaxial fatigue criteria as applied to rolling contact fatigue. Tribol. Int., doi: 10.1016/j.triboint.2010.06.003.

27 Moore, A. J. (1997) The behaviour of lubricants in elastohydrodynamic contacts. Proc. Instn. Mech. Engrs., Part 7 211, 91-106.

28 Bair, S. (2007) High Pressure Rbeology for Quantitative Elastobydrodynamics. Elsevier. Tribology series, vol. 54. 
29 Wong, P. L., Wang, R. and Lingard, S. (1996) Pressure and temperature dependence of the density of liquid lubricants. Wear 201, 58-63.

30 Lafont, P. Lafont P., Echavarri J., Sanchez-Peñuela J. B., Muñoz J. L., Diaz A., Munoz-Guijosa J. M., Lorenzo H., Leal P. and Muñoz J. (2009) Models for predicting friction coefficient and parameters with influence in elastohydrodynamic lubrication. Proc. Instn. Mech. Engrs., Part $7223,949-958$.

31 Kumar, P. and Khonsari, M. M. (2009) Traction in EHL line contacts using free-volume pressure-viscosity relationship with thermal and shear-thinning effects. $\mathcal{F}$. Tribol, doi: $10.1115 / 1.3002331$.

32 Gold, P. W., Schmidt, A., Dicke, A., Loos, J. and Assman, C. (2001) Viscosity-pressure-temperature behavior of mineral and synthetic oils. F. Synth. Lubr. 18, 51-79.

33 Echavarri, J. Echavarri J., Lafont P., Chacon E., De la Guerra E., Diaz A., Munoz-Guijosa J.M. and Muñoz J. L. (2011) Analytical model for predicting the friction coefficient in point contacts with thermal elastohydrodynamic lubrication. Proc. Instn. Mech. Engrs., Part 7 225, 181-191.
34 Stachowiak, G. W. and Batchelor, A. W. (2005) Engineering Tribology. Butterworth-Heinemann, Elsevier.

35 Boresi, A. P. and Schmidt, R. J. (2003) Advanced Mechanics of Materials. John Willey \& Sons, USA.

36 Pensado, A. S., Comuñas M. J. P. and Fernández, J. (2008) The pressure-viscosity coefficient of several ionic liquids. Tribol. Lett. 31, 107-118.

37 Larsson, R., Kassfeldt, E., Byheden, A. and Norrby, T. (2001) Base fluid parameters for elastohydrodynamic lubrication and friction calculations and their influence on lubrication capability. 7. Synth. Labr. 18, 183-198.

38 Polonsky, I. A. and Keer, L. M. (1999) A numerical method for solving rough contact problems based on multi-level multi-summation and conjugate gradient techniques. Wear, 231, 206-219.

39 Snidle, R. W. and Evans, H. P. (2009) Some aspects of gear tribology. Proc. Instn. Mech. Engrs., Part C 223, 103-141

40 Susmel, L. and Lazzarin, P. (2001) A bi-parametric Wöhler curve for high cycle multiaxial fatigue assessment. Fatigue Fract. Engng Mater. Struct. 25, 63-78.

41 Budynas, R. G. and Nisbet, J. K., Shigley's Mechanical Engineering. Desing McGraw-Hill, USA 